Res Pública Revista de Historia de las Ideas Políticas

ISSN: $1131-558 \mathrm{X}$

https://dx.doi.org/10.5209/rpub.67249

\title{
La crítica de la modernidad en el pensamiento decolonial
}

\author{
Jorge Álvarez Yágüez*
}

Recibido: 14 de enero de 2020 / Aceptado: 8 de marzo de 2021

Resumen. El presente texto se centra en la crítica que el pensamiento decolonial ha dirigido a la cultura occidental, focalizada en la modernidad, como intrínsecamente violenta y respecto de la cual las culturas que sufrieron la colonización debieran cortar radicalmente. Con el objetivo de poner en cuestión algunos aspectos centrales de este planteamiento se analizan críticamente sus conceptos de modernidad, de geopolítica del conocimiento y de cultura.

Palabras clave: modernidad; cultura; geopolítica del conocimiento.

\section{[en] The Critique of Modernity in the Decolonial Thought}

Abstract. This paper takes as its central issue the criticism that the decolonial thought has made to the Western culture, focused on modernity, as an internally violent culture. For this reason, the decolonial authors think that the cultures which have suffered the colonization should set a cut in regard of Western culture. We try to put in question some central aspects of this conception, as their concepts of modernity, culture, and geopolitics of knowledge.

Keywords: Modernity; Culture; Geopolitics of Knowledge.

Sumario. 1. El giro decolonial. 2. ¿Qué Modernidad?. 3. Geopolítica del conocimiento. 3.1 Imposibilidad de transcender el contexto. 3.2 Afuera o mediaciones. 3.3 Idealización, acrítica, paternalismo. 4. Otras epistemologías 5. Un concepto equivocado de cultura. Bibliografía

Cómo citar: Álvarez Yágüez, J. (2021). La crítica de la modernidad en el pensamiento decolonial. Res Pública. Revista de Historia de las Ideas Políticas, 24(1), 3-15.

\section{El giro decolonial}

Se ha hablado en filosofía de un giro lingüistico, de un giro pragmático; hoy debiéramos hablar de un giro descolonizador según los mismos autores que lo promueven $^{2}$. Esto, en cualquier caso, es lo que impulsa el llamado pensamiento decolonial. De el no puede decirse que sea una corriente unitaria, pues, entre sus representantes, hay relevantes diferencias, algunas hechas explícitas por ellos mismos, por Grosfoguel respecto de Quijano, por Mignolo respecto al sociólogo del derecho Boaventura de Sousa, autor reivindicado por muchos de ellos, etc. No todos, ciertamente, asumen las posiciones que el más significado en el intento de definir la mirada decolonial, el argentino de la Universidad de Duke, Walter Mignolo, ha estipulado.

En una primera aproximación, calificaríamos la mirada decolonial de culturalista, pues, aunque todos sus autores acepten la distinción capital de Quijano entre colonialismo y colonialidad y la diferenciación consiguiente entre tres colonialidades, del poder, del ser y del saber, se diría que todo es observado desde esta última. De ese modo se incurre en lo que en otro lugar hemos calificado de culturización de la política, esto es, la tendencia a juzgar elementos que tienen una naturaleza económica o social o política desde el filtro de la cultura, no ya porque este afecte a todo, lo que va casi de suyo, sino como el filtro primordial, la instancia de la que depende lo demás. Eso hace que a menudo las críticas de la colonialidad sean dirigidas a una determinada cultura, que aparece focalizada en la modernidad occidental-siendo aquí el calificativo redundante ${ }^{3}$, toda vez que suelen contemplar una relación de implicación biunívoca entre los dos términos. No pocas veces se da una generalización de la crítica de la modernidad a la crítica de Occidente tout court. Es significativo al respecto que Mignolo, por ejemplo, nos confiese que primero había formulado su concepto como "postcolonial reason" pero

\footnotetext{
Doctor por la UCM, investigador independiente, sin adscripción institucional

jorgealvarezyaguez@edu.xunta.es

E. Dussel, Politics of Liberation. A Critical World History, transl. Th. Cooper, London, SCM Press, 2011, p. 189.

Curiosamente, este es un punto que Boaventura critica a Mignolo, un excesivo culturalismo, que le llevaría a no prestar suficiente atención a las condiciones materiales, económicas. Les reprocha a los decoloniales también que en la explicación de la discriminación den prioridad al colonialismo por encima del capitalismo mismo. Al respecto, Boaventura no cree que la subordinación de las mujeres sea debida al colonialismo, tampoco al capitalismo. Boaventura considera que los decoloniales se centran más en la crítica de la modernidad occidental que en el capitalismo. Cf. B. De Sousa Santos, Una epistemología del sur, (Ed J.G. Gandarilla), México, Clacso, S. XXI, 2009, pp. 352, 353.
} 
que prefirió más tarde el de "post-Occidental reason"3. La modernidad es occidental incluso con independencia de la geografía, lo es donde quiera que se dé; la implicación es conceptual, no espacial. La modernidad se constituye en el foco de la crítica, a ella se deberán todos los males, pues se parte de la tesis de que modernidad implica capitalismo y éste, colonialismo. Hacer frente, entonces, a las estructuras que aún imperan después del fenómeno histórico del colonialismo y de la lucha anticolonial, después incluso de la obtención de la independencia, exigiría ocuparse críticamente, de manera central, del primer elemento de la cadena: la modernidad.

\section{2. ¿Qué Modernidad?}

Se entendería por Modernidad fundamentalmente esa cultura que impera en Occidente y que ha acompañado el comienzo y desarrollo del capitalismo, y dentro de la cual aún nos desenvolvemos ${ }^{4}$. Eso quiere decir -este es un punto especialmente destacado, sobre todo en los estudios del filosofo argentino-mexicano E. Dussel-que la Modernidad no se inicia ni con la revolución científica del XVII, ni con la Ilustración del XVIII o con la Revolución industrial, sino que se remonta al s. XV-XVI, en definitiva a la fecha fatídica de 1492, la de la expulsión de los judíos y del llamado "descubrimiento", aun cuando, noblesse oblige, tenga sus antecedentes en la cultura de las ciudades bajomedievales italianas ${ }^{5}$. Se hace necesario llevar el inicio al s. XV para poder dar consistencia al encadenamiento de los tres eslabones mencionados, modernidad-capitalismo-colonialismo. Al fin, no sería sino en ese momento cuando Europa empezaría a salir de su situación históricamente periférica respecto de un

W. Mignolo, Local Histories and Global Designs. Coloniality, Subaltern Knowledges and Border Thinking, New Jersey, Princeton U. Press, 2000, p. 91.

$4 \quad$ Walter Mignolo sintetiza así sus tesis al respecto: "1. No existe modernidad sin colonialidad, ya que esta es parte indispensable. 2. El mundo moderno/colonial (y la matriz colonial de poder) se origina en el siglo XVI, y el descubrimiento/invención de América es el componente colonial de la modernidad cuya cara visible es el Renacimiento europeo. 3. La Ilustración y la Revolución Industrial son momentos históricos derivados que consisten en la modificación de la matriz colonial del poder. 4. La modernidad es el nombre del proceso histórico en el que Europa inició el camino hacia la hegemonía. Su lado oscuro es la colonialidad. 5. El capitalismo, tal como lo conocemos, está en la esencia de la noción de la modernidad y de su lado oscuro, la colonialidad. 6. El capitalismo y la modernidad/colonialidad tuvieron un segundo momento histórico de transformación después de la Segunda Guerra Mundial, cuando Estados Unidos se apropió del liderazgo imperial del que antes habían gozado, en distintas épocas, España e Inglaterra". W. Mignolo, La idea de América Latina. La herida colonial y la opción decolonial, trad. S. Jawerbaum, J. Barba, Barcelona, Gedisa, 2008, p. 18.

F. Braudel se remontaría al s. XIII, y Bolívar Echevarría un poco más allá, al s. XI. Koselleck se remite al s. XV, aunque el término tardara cuatro siglos en aparecer. Marx situaba en el XVI el capitalismo reconociendo sus inicios un poco antes: "Aunque los primeros indicios de la producción capitalista ya se nos presentan esporádicamente en los siglos XIV y XV en algunas ciudades del Mediterráneo, la era capitalista solo data del s. XVI" (K. Marx, El capital, t. I, cap. XXIV, trad. W. Roces, México, FCE, p. 609). F. Braudel, El mediterráneo, México, FCE, 1987; B. Echevarría, Las ilusiones de la modernidad, México, UNAM, 1997; R. Koselleck, "Modernidad", en Futuro pasado. Para una semántica de los tiempos históricos, Barcelona, Paidós, 1993.
Oriente más poderoso y culto, de diferente religión; desplazada respecto al imperio otomano (Constantinopla es conquistada en 1453), al mundo islámico y asiático. Solo con la plata de las minas de Potosí, con la riqueza venida de América, Europa habría podido empezar a constituirse en centro; el sistema-mundo arranca ahí. Gracias a Latinoamérica (Norteamérica no entrará en escena hasta el XVII), Europa habría podido competir con más éxito con sus rivales turcos, musulmanes y orientales en general. Esto le habría permitido postularse como centro mundial, lo que conseguiría definitivamente con la Revolución industrial. El siglo XVII no sería sino una consecuencia de lo anterior, marcado por el paso de la relevancia del Mediterráneo a la del Atlántico. Holanda e Inglaterra se irían sumando como potencias coloniales y en el siglo XVIII Portugal y España perderían ya su preeminencia; estaríamos, entonces, en una segunda etapa de la Modernidad. De no haberse descubierto el Nuevo Mundo, Europa poco habría cambiado en términos culturales. El cambio general (en filosofía, ciencia, técnica, política, economía, religión, etc.) vendría de la mano del nuevo continente descubierto. El despertar de Europa de su sueño medieval ocurriría de oeste a este y de sur a norte: partiría de España y Portugal, y algo menos del Renacimiento italiano, y se iría extendiendo a Francia, Alemania, Inglaterra y Países escandinavos ${ }^{6}$. Sin dejar en ningún momento de considerar que ese nuevo centro del mundo termina reductivamente por identificarse con el norte europeo, como se mostraría por antonomasia en la Historia de Hegel donde todo conduce a la fase última de dominio del mundo germánico.

Dussel contrapone su concepción al enfoque, tenido por provinciano y endógeno, que se habría sostenido de Weber a Habermas, de una Europa moderna definida, como aparece en este último, por la Reforma, la Ilustración y la Revolución francesa -a la que a veces se añade el parlamentarismo inglés y el humanismo renacentista italiano-, y que se caracterizaría como un pensamiento de emancipación (Kant), siendo el XVIII su siglo par excellence $e^{7}$.

El enfoque de Dussel se diferencia también de otras perspectivas, como la de Wallerstein (o Arrighi), que si bien situarían el inicio del capitalismo en el s. XV, no así el de la modernidad ${ }^{8}$, o la de los poscoloniales de primera hornada como E. Said (centrada en Oriente Medio y en la colonización de Argelia, 1830), G. Spivak

E. Dussel, Politics of Liberation, op. cit., pp. 182 ss. De lo que no se apercibe Dussel es que Europa no necesitaba del Nuevo Mundo para el descubrimiento del Otro, lo tenía en la imagen del esclavo doméstico con el que convivía. Él nunca se refiere a esto, sí a los esclavos africanos, pero sin señalar su presencia en la vida cotidiana europea. Sobre este punto, nos permitimos: J. Álvarez Yágüez, "La esclavitud invisible", Debats, no 129, 2015/4, pp. 42-57.

E. Dussel, "Europe, Modernity and Eurocentrism", Nepantla: Views from South 1, 3, Duke U. Press, 2002, pp. 469-470.

8 B. de Sousa comparte la idea de una modernidad iniciada en el XVI pero el capitalismo sería posterior: "la modernidad se transformó en un paradigma sociocultural antes del triunfo del capitalismo" (Crítica de la razón indolente, Bilbao, Desclée de Brouwer, 2003, pp. 131-132). "Concibo la modernidad occidental como un paradigma sociocultural que se constituye a partir del s. XVI y se consolida entre finales del s. XVIII y mediados XIX" (Conocer desde el sur. Para una cultura política emancipatoria, Lima, Facultad de C. Sociales, 2006. p. 42). 
(que sitúa el arranque en 1750)9 o D. Chakrabarty; todos ellos, influidos por el modelo del colonialismo británico, tenderían a situar la modernidad en el periodo ilustrado. Esta otra perspectiva significaría para los decoloniales una perspectiva sesgada, debido a la postergación constante de la experiencia latinoamericana.

Las consecuencias de retrotraer, creemos, por lo demás, que acertadamente, la modernidad al momento renacentista son de calado. Hacerlo era, como apuntamos, crucial, si se quería establecer una relación intrínseca entre modernidad y colonialidad, pues ahí se daría el inicio de los dos primeros imperios coloniales: el español y el portugués. Esto comportaba la tarea de traer a la luz la aportación hispano-portuguesa a la construcción de la modernidad. Y es a lo que se entrega E. Dussel, que nos propone entender, entonces, que antes de 1637, de la aparición del Discurso del método, antes de la formulación del ego cogito, esto es, de la filosofía que se toma emblemáticamente como definitoria del pensamiento moderno, habría habido todo un rico mundo cultural sin el que no se explicaría su emergencia. De ese mundo formarían parte brillante: la escolástica española, la de la Escuela de Salamanca, que estaría en la base de la filosofía jurídica moderna, de Grocio en adelante; la figura descollante del jesuita Francisco Suárez, el verdadero "primer filósofo moderno" y no Descartes (en otro lugar nos dirá que ese lugar lo ocupa Sepúlveda), cuyas Disputationes Metaphysicae,1597, influirían de Baumgarten, Leibniz y Wolff a Kant; el influyente manual de Lógica, muy usado por los jesuitas, del mexicano Francisco Rubio (s. XVI-XVII); la propia fundación de los jesuitas por Ignacio de Loyola, en uno de cuyos colegios, La Flèche, es bien sabido, se formó el Cartesio, y cuyos ejercicios espirituales no dejan de traslucirse en su obra. Dussel destaca también al filósofo y teólogo portugués Pedro de Fonseca (XVI) -que influiría en Suárez y en otros autores portugueses como Marcos Jorge, Cipriano Soares, Pedro Gomes, Manuel de Gois; su obra tendría repercusión en la filosofía europea. Todos esos autores destacaron la importancia del método, que ejemplificaban en las matemáticas. Habría que citar también al portugués Francisco Sánchez (XVI) y al sefardí, nacido en Medina del Campo, Gómez Pereira, autor de un tratado científico autobiográfico, que enunciará el: "nosco me aliquid noscere, et quidquid noscit est, ergo ego sum".

Esto explicaría una apertura mayor de esos autores a las perspectivas críticas que la modernidad misma ofrece, y que no sean, en consecuencia, tan radicalmente negativos con la misma, pues su periodización histórica hace que el colonialismo sea coetáneo con una modernidad que ya era crítica consigo misma. Los descoloniales se deshacen de la carga ilustrada que poscoloniales como Said, como Paul Gilroy aun querían mantener. Según Grosfoguel, desde la perspectiva de 1492 ya toda la crítica ilustrada al absolutismo, en favor del individuo, de la tolerancia, etc. se vería como eurocéntrica, no cuestionadora del colonialismo. Grosfoguel olvida tres puntos: 1) Que en la modernidad sí hubo crítica de la violencia colonial, de la esclavitud si bien es verdad que no fue lo dominante. 2) Que sobre la colonialidad española ya desde el primer momento también hubo voces críticas, como las de Montesinos, Las Casas y Vitoria. 3) Que aun con independencia de que se diesen de facto o no críticas a la realidad colonial, habría que analizar si la teoría no las permitía de iure; sobre esto último volveremos más adelante. R. Grosfoguel, "Hacia un pluri-versalismo transmoderno decolonial", en Tabula Rasa, Bogotá, nº.9, jul.-dic. 2008, pp. 199-215.
No serían, pues, ideas epigonales de la cultura medieval lo que acompañaría a los barcos hispano-portugueses.

Pero lo importante no sería limitarse a registrar esa aportación cultural invisibilizada -que el crítico Dussel, como Boaventura, no dejan de recordarnos con orgullo, curiosamente, por muy vinculado a la raíz del mal que tal cultura pudiera estar ${ }^{10}$ - sino comprender cómo el atroz fenómeno de la conquista, de la explotación a través del sistema de encomienda y mita, de la violencia que todo ello significó, están en la base de una cultura que se iría conformando como elemento legitimador de ese mundo. De ahí la afirmación de Dussel, tantas veces repetida, de que el ego cogito viene anticipado por un ego conquiro, cuya primera manifestación se encontraría en Ginés de Sepúlveda, pues se interpreta que el sujeto abstracto aquél y toda la arquitectura conceptual que le acompaña, las divisiones binarias que se suponen definitorias del pensamiento moderno (mente/cuerpo, sujeto objeto, espíritu/materia, cultura/natura, razón/pasión) configuran un pensamiento inevitablemente cosificador y violento ${ }^{11}$. De suerte que la filosofía, emblema de toda una cultura, no vendría sino a elevar a concepto una práctica que estaba en sus inicios. La legitimación que vehiculaba era a la vez elemento operativo de primer orden, no hay conquista sin modernidad.

Toda esta implicación es más enunciada que argumentada, pero el estilo de este pensamiento decolonial es eminentemente declarativo. Para Dussel el comienzo de la filosofía moderna se da con el intento de Sepúlveda de justificar la dominación; Sepúlveda es "el primer filósofo político moderno con un sentido atlántico de la problemática (no solo mediterráneo)"12. Que hubiera imperios, explotación, patriarcalismo, violencia, antes de la modernidad no es objeción atendible; basta con el mero enunciado de aquella implicación, la sugerencia de su verosimilitud, aun cuando haya una cierta y nada simple distancia entre una estructura teórica y sus atribuidos efectos, entre la violencia metafórica de toda operación conceptual, la formulada objetivación cosificadora de la teoría moderna del conocimiento, de sus divisiones categoriales, etc. y el genocidio, el sometimiento y la esclavización ${ }^{13}$.

Tampoco parece ofrecerles dificultad alguna el curso que posteriormente ha tomado la modernidad, pues se muestran indiferentes a que el proceso de moderniza-

Vemos, según esto, a Boaventura enfatizar la relevancia de Portugal, que encabezaría, no España, la primera modernidad; discrepa al respecto de Dussel, y menciona como ejemplo la influencia de un Pedro Fonseca, al que leían Descartes, Leibniz y Kant. B. De Sousa Santos, Una epistemología del sur, op. cit., pp. 350, 362.

11 E. Dussel, 1492, El encubrimiento del otro. Hacia el origen del “mito de la modernidad”, La Paz, Plural, 1994, pp. 47 ss; R. Grosfoguel, "Hacia un pluri-versalismo..."op. cit., pp. 202 ss.

12 E. Dussel, Politics of Liberation, op. cit., p. 192,

13 Se procede enunciativamente más que argumentativamente: Así, para Dussel, Guamán pone al descubierto la culminación del ego conquiro en el ego cogito, el sujeto autocentrado, remedo de Dios que pone el mundo bajo su propio control, aunque realmente lo que puede leerse en Guamán, y no es poco, es la denuncia de la arrogancia de los españoles, y sus muchos daños. Para Dussel el ego cogito cartesiano implicaba de por sí la conversión de los indios en máquinas a explotar. E. Dussel, Anti-Cartesian Meditations and Transmodernity. From the Perspectives of Philosophy of Liberation, (ed, A. A. Vallega, R. Grosfoguel), The Hague, Amrit P, 2008, p. 108. 
ción se haya autonomizado y desvinculado de sus presupuestos ilustrados. Esta es la tesis de Arnold Gehlen. Para el pensamiento decolonial, en realidad esto no sería posible dada la inextricabilidad entre capitalismo, modernidad y razón occidental. No habría, entonces, la posibilidad de reivindicar de algún modo los presupuestos olvidados en contra de la autonomización del capitalismo.

No se distingue entre la potencia de una teoría y las doxai de sus mismos autores, cuando aquella suele estar muy por encima de estas, como no se repara en la frecuente multiplicidad de sus usos. Spinoza puede callar acerca de la realidad de la esclavitud, base comercial de sus compatriotas, pero su teoría puede ser utilizada contra aquella; Poullain de la Barre puede usar el sujeto cartesiano para cuestionar la exclusión de la mujer ${ }^{14}$; al igual que hace Olimpe de Gouges con Rousseau, y esto a pesar de él. En fin, la revolución haitiana, antiesclavista se hizo sobre los ideales de la Ilustración y contra buena parte de las opiniones de sus promotores, pero fue acogida con júbilo en muchos círculos intelectuales europeos, como fue el caso del grupo reunido en torno a la revista alemana Minerva ${ }^{15}$.

Por otra parte, tampoco hay que olvidar las voces que, frente a la tendencia dominante, se alzaron contra la ignominia en las colonias, como, por citar un ejemplo notable, la que evidencia el escrito ilustrado Historia filosófica y política del establecimiento y del comercio de los europeos en las dos Indias -de varios autores, entre ellos Diderot ${ }^{16}$-, que rechaza el colonialismo, su violencia, el racismo, la dominación y la tiranía.

14 P. De la Barre, De l'égalité des deux sexes, discours physique et moral où l'on voit l'importance de se défaire des préjugez (1673): "Un tratado donde se extraen con una lógica impecable las derivaciones, en relación con los derechos de las mujeres, de la lucha cartesiana contra el prejuicio, el argumento basado en la autoridad, la costumbre y la tradición. Sobre estas bases, así como sobre la idea de que «l'esprit n'a pas de sexe»-o, si se prefiere, «l'esprit est de tout sexe», corolario del dualismo cartesiano mente-cuerpo-, se argumentan reivindicaciones feministas como la del sacerdocio, el ejercicio de la judicatura, del poder político, el desempeño de las cátedras universitarias, el acceso a los altos cargos del ejército: todo ello apoyado, en suma, en una educación totalmente igualitaria" (C. Amorós, "El feminismo, senda no transitada de la Ilustración”, Isegoría, 1, 1990, p. 140.

15 S. Buck-Morss, Hegel y Haití. La dialéctica amo-esclavo: una interpretación revolucionaria, trad, F. Rodríguez, B. Aires, Norma, 2005, pp. $44 \mathrm{ss}$.

16 M. Galceran ("Raza, Clase, Género. Descolonizando a la izquierda. Los estudios poscoloniales y decoloniales y la intelectualidad europea", Viento Sur, 160, oct. 2018, pp. 27-34) le critica su registro moralista y su visión del indígena, la tópica del buen salvaje. La crítica de la esclavitud, si bien nada frecuente, puede encontrarse en algunos autores, de diversa manera: en formas solo conceptuales sin referencia al dato histórico o con toda radicalidad incluyendo referencias empíricas. Ello evidencia que no había condición epistémica de imposibilidad alguna. En una gradación de menor a mayor radicalidad podría mencionarse en un grupo a Rousseau, a Helvetius y Voltaire, y en otro a Diderot, Condorcet (miembro de la sociedad abolicionista Amis des Noirs), Francis Van den Enden. El escrito de Condorcet, Reflexions sur l'exclavage des nègres (1781) proponía la abolición de la esclavitud; Van den Enden, el republicano maestro de Spinoza, propuso la abolición en la Holanda envuelta en el tráfico esclavista, ya en 1662 en su Breve relato de la Nueva Holanda. Cf. D. Tatián, "La potencia de los esclavos. Conjetura sobre un silencio de Spinoza", Revista Co-herencia Vol. 15, no 28, en.-jun. 2018, pp. 225-244.
Igualmente tendría que registrarse la confrontación que se da en el seno de lo que, como un todo, se aborda como pensamiento moderno. Hay que recordar que la crítica al pensamiento deslocalizado, al intento de un sistema conceptual absolutamente apoyado en fundamentos inconmovibles, se ha reiterado en el curso del propio pensamiento occidental. La crítica al sujeto cartesiano, el cuestionamiento de las divisiones modernas natura/ cultura, sujeto/objeto, espíritu/materia, razón/afectos, etc., puede verse en su locus por antonomasia, en Hegel, un autor en el que ciertamente se encuentran tantas observaciones justificatorias del "occidentalismo". Hegel era muy consciente de las consecuencias históricas de todo esto, del lado autoritario de la autoconciencia, del "principio de subjetividad como un principio de dominio", de sus consecuencias en el terror de la revolución francesa, o en el desgarro de una totalidad vital; recordemos cuando afirmaba, anticipando a HorkheimerAdorno, "o bien el hombre es convertido en objeto y oprimido o tiene que convertir en objeto y oprimir a la naturaleza" ${ }^{17}$. Por eso resulta insuficiente este tipo de crítica hecha al pensamiento moderno. Es correcta, por ejemplo, cuando se denuncia el Hegel de la filosofía de la historia que desprecia las culturas no europeas, pero resulta incapaz de mostrarnos la conexión conceptual entres estas doxai y la episteme o teoría. Y, así, se acaba en una confusa denuncia de la razón moderna, en la que en ningún momento se entra en su complejidad interna, en sus diferencias. No se hace nada que se asemeje por ejemplo a la crítica que Hegel hizo de la misma, y de sus anteriores codificaciones en Kant o Fichte. No se hace separación alguna de elementos; no vemos las distinciones de Marx, de Weber o de Lukács entre lo emancipador y lo represivo, lo reconciliador y lo desgarrador.

En fin, la crítica de sí que realiza la misma razón moderna puede proseguirse, ya más tarde, de la física cuántica a la neurología, de Heisenberg, Heidegger, Adorno, Wittgenstein al postestructuralismo y el posmodernismo. Todo el paradigma del racionalismo moderno (fundamentos, tabla rasa, certeza, modelo euclidiano, formalismo...) ha sido pulverizado por la propia crítica occidental. Habría que reconocer que tal capacidad de autocrítica está en relación con uno de los rasgos más singulares de esa cultura, el de que haya llegado a constituir el sometimiento a crítica de todo aquello que se

Es verdad que el concepto de estado de naturaleza de los contractualistas pudo servir a algunos para sostener enfoques despreciativos del mundo americano, por cuanto se suponía que aquellos hombres no tenían conveniencia de un estado más desarrollado como el Estado civil, como, por ejemplo, J. Locke. Pero también, contra Hobbes, hubo toda una radical corriente ilustrada (Lahontan, Radicati, Tyssot de Patot) que se deshacía en alabanzas a la vida del hombre en ese estado, con virtudes morales superiores a las de los hombres europeos. Estos habrían sido viciados por la propiedad y la desigualdad. Fueron predecesores en esto de Rousseau. No tenía por qué ser un indígena como Guamán, el único que hablase de las virtudes de hombres semejantes. Cf. J. I. Israel, Radical Enlightenment, Philosophy and the Making of Modernity 1650-1750, Oxford U. Press, 2001, pp. 272-274.

17 Para este punto ver el texto de Habermas del que tomamos la cita: El discurso filosófico de la modernidad, trad, M. Jiménez Redondo, Madrid, Taurus, 1989, pp. 42, 399. 
postule como verdad en elemento esencial para su mantenimiento tanto en ciencia como en filosofía ${ }^{18}$.

La crítica operada por el pensamiento decolonial procede, sin embargo, de manera totalizante, sin hacer distinciones, como si filosóficamente hablando la modernidad fuera un todo homogéneo donde no hay pluralidad ni autocrítica alguna. Habría que distinguir diversas modernidades: la del norte, la del sur, la protestante y la católica, la escéptica de Erasmo, Rabelais y Montaigne por un lado, y la de las certezas de Descartes y Newton por otro, la del humanismo del XVI, de orientación más práctica, frente al racionalismo teorético de la ciencia del XVII ${ }^{19}$. Pluralidad, pues, en su diacronía: Stephen Toulmin opone el abierto humanismo del Renacimiento, del XVI, al estrechamiento científico del XVII. Desde esta perspectiva podríamos ver que mucho de lo que reprochan a la modernidad los decoloniales (saber desencarnado, descontextualizado) es justamente algo que no se codifica hasta el siglo XVII. El XVI habría sido más tolerante que el XVII, en que uno podía ser fácilmente degollado por su creencia. En fin, la modernidad de Descartes no es la de Spinoza, por no entrar en disputas más finas entre cartesianos y newtonianos, en las diferencias entre republicanos y protoliberales ${ }^{20}$.

La modernidad presenta muchas caras, y a su pluralidad habría que añadir su conflictividad (guerras y revoluciones, persecuciones y censuras). Incluso socialmente cabe distinguir muy distintas acepciones del paradigma moderno, piénsese por ejemplo, en el siguiente caso: los inconformistas republicanos ingleses partidarios de una materia activa, espontánea, que consideraban pareja a la tesis de la capacidad autónoma para la acción por parte del pueblo, frente a los conservadores monárquicos que seguían la tesis de su carácter inerte reafirmada por

18 E. Dussel trata de indicar diferencias pero es inconsecuente y la tendencia a la totalización se impone. Nos dice en algún momento que reconoce un contenido emancipador en la razón ilustrada, que no condena la razón sino tan solo el mito de lo irracional que esconde, pero después, todo su planteamiento no es consistente con esta oportuna salvedad. El pretende, por momentos, focalizar su crítica en una denuncia atinada, la de lo que llama "mito de la modernidad" (1492 el encubrimiento... op. cit, p. 70), esto es, el desprecio absoluto por el Otro, por la otra cultura, considerada inferior y bárbara, mito legitimador de la dominación, que considera útil también para los dominados. De este modo, el hombre moderno se desculpabiliza, y hace responsable de su dominación a sus propias víctimas. Los sacrificios se presentan como necesarios para el progreso. Con el concepto de transmodernidad Dussel pretende evitar los extremos del irracionalismo postmoderno y del universalismo vacío del racionalismo, que aprecia en Habermas y otros. Sobre este concepto, cf. R. Castro Orellana, "Sistema mundo y transmodernidad. Una lectura crítica", en Política Común, vol. 10, 2016, https://doi.org/10.3998/ pc.12322227.0010.004.

19 Para S. Toulmin, esos son los dos orígenes de la modernidad: el literario y humanista del Renacimiento, y el de la ciencia física del XVII. S. Toulmin, Cosmópolis. El trasfondo de la modernidad, trad, B. Moreno, Barcelona, Península, 2001, pp. 77, 124.

20 A. Domènech criticaba esta frecuente homogeneización ciega: "lo cierto es que en el desbaratado mundo académico posterior a la II Guerra Mundial, en cambio, se impuso más bien a diestra y siniestra la arbitraria idea de una supuesta «modernidad» homogénea, una noche en la que todos los gatos son pardos, y en la que dan lo mismo Grocio que Vitoria; Hobbes que Locke; Gentz que Kant; Bentham o Burke que Adam Smith" ("Prólogo" a D. Casassas, La ciudad en llamas. La vigencia del republicanismo comercial de Adam Smith, Barcelona, Montesinos, 2010, p. 20.
Newton $^{21}$. Según sectores sociales y lugares, del centro (Londres, París) a la periferia (Escocia, Montpellier) la cultura variaba, dándose en estos segundos mayor libertad de ideas, menor presión para aceptar un código.

Tampoco se hace diferencia entre umbrales epistemológicos o entre niveles de discurso. Filosofía, ciencia e ideología son tratadas indistintamente, todas ellas son reos de la misma acusación, sin advertir siquiera que la particularización o dependencia del contexto no es lo mismo en unas que en otras, que es fácil hablar de literatura andaluza pero no tanto si se trata de física o matemática. Según esto, R. Grosfoguel, por ejemplo, no tiene reparo en decir que las ciencias sociales son ciencias coloniales; y W. Mignolo procede del mismo modo nivelador con lo que distingue como "relato europeo" y su "marco filosófico" de referencia, expresando uno y otro lo mismo, sin parar mientes en que este acaso posibilite críticas de aquel ${ }^{22}$.

El enfoque decolonial comprende la modernidad como un todo que responde al concepto althusseriano de totalidad temporal posibilitadora del corte de esencia, en que en cualquiera de sus elementos puede leerse expresado lo que podríamos denominar hegelianamente el mismo Espíritu ${ }^{23}$.

En el fondo se maneja un concepto de cultura como una esfera homogénea cerrada, con lo que no deja de incurrirse en la incongruencia de criticar en el otro lo que también es propio, pues esa misma idea de cultura ha sido tomada del occidente criticado. Volveremos sobre esto. Se critica, con razón, que Occidente haya construido una historia de sí en que surge, ex nihilo, de Grecia y llega en perfecta continuidad a Alemania, como se mostraría en Hegel o Burckhardt ${ }^{24}$, y, al tiempo, no se repara en que el concepto de cultura que está ahí en curso es el mismo que se maneja en la crítica. Siendo esto así, puede afirmarse, en palabras de Mignolo, la continuidad del cristianismo al marxismo pasando por el liberalismo en sucesivos macrorrelatos que habrían circulado en Occidente ${ }^{25}$. O que "el proyecto" de la modernidad no es emancipatorio sino civilizatorio, e inherentemente colonial (Grosfoguel).

La homogeneización, a menudo, se extiende diacrónicamente, como si los cambios en cinco siglos no afec-

\footnotetext{
S. Toulmin, op. cit, p. 174.

22 Lo escandalosamente sorprendente es que de antemano rechace como sospechoso el intento de afinar y precisar: "El problema es que muchas veces la «historiografía rigurosa» es cómplice de la modernidad (...). En ese sentido, el argumento en favor del rigor disciplinario es, en realidad, una maniobra que permite perpetuar el mito" (W. Mignolo, La idea de América Latina, op. cit., p. 40).

23 L. Althusser, E. Balibar, Para leer El capital, trad, M. Harnecker, Madrid, S. XXI, 1972, p. 144.

24 Este punto crítico se repite en los diversos autores decoloniales. Sin embargo, debiera precisarse pues la crítica es válida según que época y autores, pues hace tiempo que la investigación ha puesto de relieve un origen híbrido y de préstamos, por lo demás característico de la mayoría de las culturas. G. K. Bahmbra ha tratado con más cuidado esta idea y aportado abundante información en: Rethinking Modernity: Postcolonialism and the Sociological Imagination, Palgrave MacMillan, 2007, cf. cap. 4.

25 "Geopolíticas del conocimiento y colonialidad del poder", Entrevista a Walter Mignolo" por C. Walsh, en C. Walsh, F. Schiwy y S. Castro-Gómez, Indisciplinar las ciencias sociales. Geopolíticas del conocimiento y colonialidad del poder: perspectivas desde lo andino, Quito, U. Andina Simón Bolívar, 2002, cap. 1.
} 
taran a nada esencial para nuestro problema, y se escribe sin precisión como si la duda acerca de la humanidad de los indígenas que Sepúlveda había planteado en su momento se mantuviera en el tiempo sin más, sin distinguir en qué nivel discursivo se daba en cada época, o la perspectiva respecto de la esclavización. Y no se repara en ningún momento en la situación singular de que los españoles no pusieron en cuestión la esclavitud propia pero sí la americana; no, desde luego, la africana.

Otro ejemplo de esta diacronía homogeneizante lo encontramos en la descripción del racismo de Grosfoguel ${ }^{26}$. Este superpone la definición de racismo de F. Fanon a los esquemas de Quijano y de Boaventura. Fanon definía el racismo, de manera amplia, como "la jerarquía de superioridad/inferioridad sobre la línea de lo humano", definición que Grosfoguel hace corresponder con la división que el concepto de colonialidad del poder de Quijano traza entre la línea del ser y del no-ser, y con el planteamiento de Boaventura respecto del denominado pensamiento abismal, que distingue entre la zona gestionada a través de los mecanismos de regulación y emancipación, por una lado, y la zona de apropiación y violencia, por otro; mientras que en la primera se reconocería al otro y se le atribuirían derechos, y en ella los conflictos (de clase, género, cultura) serían regulados, en la segunda zona nada de esto sucedería. Es este un atractivo enfoque pero no es sostenible como tal desde un punto de vista diacrónico. Un esquema así tendría que ser aquilatado y observar cómo se cumple en cada momento histórico.

\section{Geopolítica del conocimiento.}

Se entiende, particularmente en W. Mignolo, la denominada geopolitica del conocimiento - a veces también se habla de corpo-política del conocimiento-, con un sentido geográfico determinista, en el que el lugar de enunciación es la clave explicativa de todo contenido ${ }^{27}$. De este modo, ni siquiera las críticas de calado que se han

$26 \quad$ R. Grosfoguel, "What is racism? Zone of being and zone of nonbeing in the work of Frantz Fanon and Boaventura de Sousa Santos", en J. Cupples, R. Grosfoguel (edited by), Unsettling Eurocentrism in the Westernized University, New York, Routledge, 2019, pp. 264273.

27 "La geopolítica del conocimiento (los cimientos históricos locales del conocimiento) va de la mano de la política corporal del conocimiento, es decir, la base biográfica individual y colectiva del conocimiento" (W. Mignolo, La idea de América Latina, op. cit., p. 35). Grosfoguel, apoyándose en Dussel, dice respecto del sujeto cartesiano: "Recordemos que Descartes escribía su filosofía desde Ámsterdam, justo en el momento en que Holanda pasa a ser centro del sistema-mundo a mediados del siglo XVII. Lo que Enrique Dussel nos dice con esto es que las condiciones de posibilidad políticas, económicas, culturales y sociales de que un sujeto asuma la arrogancia de hablar como si fuera el ojo de Dios, es el sujeto cuya localización geopolítica está determinada por su existencia como colonizador/ conquistador, es decir, el Ser Imperial" Y cuando es la concepción del sujeto trascendental kantiano la que sustituye a la cartesiana, entonces se nos dice que Holanda es sustituida por otras potencias como la alemana en el juego imperial: "La geografía de la razón cambia con Kant pues él escribe su filosofía desde Alemania en el siglo XVIII, justo en el momento en que otros imperios en el noroeste de Europa (incluidos Francia, Alemania e Inglaterra) desplazan a Holanda y en competencia entre sí constituyen el nuevo centro del sistema-mundo" (R. Grosfoguel, "Hacia un pluri-versalismo transmoderno decolonial”, op. cit., pp. 202, 204). dado dentro de la designada cultura occidental, a las que antes nos referíamos, como tampoco las del postmodernismo, estructuralismo y postestructuralismo, pueden ser aceptadas, aun cuando solo fuera porque no tematizan la colonialidad, por mucho que esto pudiera ser mera contingencia en su problemática en tanto que en su arquitectura conceptual no hay nada que impidiera incluirlo en su programa de investigación. Para el pensamiento decolonial es esencial indicar que esas corrientes, con las que, por lo demás, todo el mundo observa cierta convergencia, por el hecho de ser europeas, son eurocéntri$\operatorname{cas}^{28}$. Esto explica el distinto tratamiento por parte de Mignolo de Las Casas y de Guamán Poma, incluyendo al primero, sorprendentemente, dentro de lo que llama "perspectiva europea", incapaz de tematizar la esclavitud, en contraste con la "perspectiva afroamericana" 29.

Ese determinismo, o tendencia al mismo más o menos acentuada según textos y autores, ha generado tensiones internas a la corriente, de manera que Mignolo reprocha a Boaventura el que hable desde Europa, por muy al sur que se sitúe y el sociólogo portugués protesta porque considera atinadamente que "biografía y bibliografía son inconmensurables" ${ }^{\prime 30}$, que ha de separarse nacimiento y punto de vista. Por su parte, Grosfoguel acusa a Quijano de no citar suficientemente a los autores que no se expresan en las lenguas imperiales; y Dussel y Mignolo discrepan de algunas de las tesis Wallerstein sobre el sistema mundial ${ }^{31}$.

\subsection{Imposibilidad de transcender el contexto.}

Ese determinismo no permite al sujeto de enunciación trascender su contexto por mucho que se esfuerce en

Todos se afanan por distanciarse de lo que les es tan próximo, particularmente del postmodernismo: Grosfoguel lo usa como criterio para diferenciarse de los poscoloniales. Autores como Foucault, Derrida, Lacan, Gramsci y Marx, que estima que permanecerían dentro del supremacismo de la episteme occidental, serían base del pensamiento poscolonial. El poscolonialismo seguiría a la postmodernidad, lo que explicaría su inexistencia antes de 1980. En otro lugar afirma la compartida tesis: "La posmodernidad es una crítica eurocéntrica al eurocentrismo. Reproduce todos los problemas de la modernidad / colonialidad" (Ibidem, p. 212).

Mignolo orilla la crítica del pensamiento postmoderno valiéndose de su especial modo de entender la geopolítica del conocimiento: "Playing with words, one could say that postmodemity is the discourse of countermodernity emerging from the metropolitan centers and settler colonies, while postcoloniality is the discourse of countermodernity emerging from deep-settler colonies (e.g., Algeria, India, Kenya, Jamaica, Indonesia, Bolivia, Guatemala) where coloniality of power endured with particular brutality". Y, fiel a su determinismo geográfico, lo distribuye de este modo: "The emphasis on postmodernity (instead of postcoloniality) in a settler colony that became a world power helps us to understand the attention that postmodernity has received in Latin America, particularly in Atlantic continental coast countries close to Europe and far away from the Pacific coast and dense Amerindian population" (W. Mignolo, Local Histories and Global Designs, op. cit., p. 99).

29 W. Mignolo, La idea de América Latina, op. cit., pp. 17, 43 ss. Cf. R. Castro Orellana, "Diferencia colonial y pensamiento fronterizo. El privilegio de Walter Mignolo", en D. Abraldes (coord.), Ideas que cruzan el Atlántico: Utopía y modernidad latinoamerican, Madrid, Escolar y Mayo, 2015, pp. 211-232.

30 B. de Sousa Santos, Una epistemología del sur, op. cit., p. 360.

31 Cf. sobre el punto: W. Mignolo, Local Histories... op. cit., pp. 49 ss.; E. Dussel, Hacia una filosofia politica crítica, Bilbao, Desclée de Brouver, 2001, pp. 387 ss, 345 ss. 
ello. Para Mignolo la crítica de la razón postoccidental va engranada siempre con historias locales; este lazo es esencial. El problema es que ese lazo no permita trascendencia alguna respecto del contexto en el que se anuda; ese es el punto teórico relevante. Ese es el problema también de su concepto de razón situada -a diferencia, por ejemplo, del de una sefardí nacida en Estambul, turco-americana como es Seyla Benhabib.

No hace falta recurrir al antropólogo argentino Rodolfo $\mathrm{Kusch}^{32}$ para saber que la filosofía griega es una respuesta a problemas históricos de Grecia, pero la cuestión no es si hay un nexo entre historia y filosofía, sino si el contexto impide todo grado de trascendencia, pues en ese caso el interés por cualquier otro autor fuera de nuestro lugar y tiempo sería tan solo puro historicismo y erudición.

En algún momento Mignolo se enfrenta a la teoría habermasiana de los intereses del conocimiento ${ }^{33}$, para rechazar su propuesta como excluyente de otros planteamientos más históricos. Trata de hacer ver que Habermas, aunque pretenda unos intereses universales inscritos en el conocimiento, en realidad solo está hablando desde una determinada cultura y desde la influencia perdurable de la cultura de la Ilustración. Mignolo, con su propuesta de historias locales y diseños globales, pretende hacer ver cómo Habermas da saltos de lo primero a lo segundo. Mignolo acierta, en efecto, al señalar condicionantes históricos y lagunas (la falta de lo excluido: colonialidad), pero se equivoca al querer transformar en intereses empíricos sin más lo que son intereses constitutivos, transcendentales. Sería de vital importancia que tratase de probar desde esa óptica que cuando un aymara, quechua o criollo español habla no está presuponiendo determinado interés (de acuerdo comunicativo, de validez, de simetría), de lo contrario la crítica no logra lo que se propone.

La escritura de Mignolo no ofrece precisiones, y tesis que podrían ser aceptables, como la de que hay "lazos epistemológicos entre localización geohistórica y producción teórica", entre el locus de producción y su producto, el conocimiento, pierden su valor al no ofrecernos explicaciones teóricas, pues no se nos dice en qué consisten exactamente tales lazos, cuál es su alcance, hasta dónde impide la aplicación de un criterio de validez. Sorprende que nunca se cite a un solo epistemólogo o filósofo de la ciencia. Mignolo declara que el locus enunciationis toma prioridad sobre la instancia de representación, pero a continuación no explica el proceso entre uno y otro, ni tampoco cómo se salvaría de tal modo el relativismo inevitable ${ }^{34}$.

R. Grosfoguel plantea el concepto de racismo epistémico para sostener que la teoría crítica del lado del ser, de Occidente, solo reconoce a un otro interior a esa zona y desconoce el otro exterior, al que no se toma en serio y cuyos conocimientos desprecia. Por esto sería racista además de imperialista-colonial, si bien "de izquierda". El caso es que, para Grosfoguel, tampoco sería válida si tomara en cuenta al otro del lado del no-ser, pues no

\footnotetext{
W. Mignolo, Local Histories... op. cit., pp. 162-163.

Ibidem, pp. 145 ss.

34 W. Mignolo, Local Histories and... op. cit., pp. 15, 119.
}

podría evitar pensarlo desde la experiencia frustrante del otro del lado del ser. "El problema es que la teoría crítica producida desde la zona del ser no pensó los conflictos sociales ni las particularidades coloniales de la zona del no-ser. Y si los pensó, lo hizo desde la perspectiva de la experiencia histórico-social de la zona del ser. De manera que la imposición de esta teoría crítica desde la zona del ser hacia la zona del no-ser constituye una colonialidad del saber desde la izquierda" ${ }^{35}$. De esa suerte, la teoría crítica occidental nunca podría superar su contexto. Una excepción, con todo, parece presentarse. Frente a la tendencia a la ceguera occidental hacia las experiencias del otro del área del no-ser, Grosfoguel sitúa la aportación de la sociología de las ausencias y de las emergencias de Boaventura.

La geopolítica del conocimiento critica la episteme moderna como la de un conocimiento descontextualiza$d o$, desencarnado, en la que se exige esa operación de abstracción y trascendencia para producir enunciados válidos. Es una crítica que, como hemos dicho, hasta cierto punto ya ha hecho la propia modernidad. Se procede con afirmaciones de carácter general, sin tener en cuenta las diferencias de géneros, de formas epistemológicas (ciencia, filosofía, textos literarios, ideología). Y como contestación, además, se incurre en el error de la inversión, de la determinación localista. Uno y otro aspecto hacen que no se comprenda el alcance y efectos de la contextualidad; se critica, por ejemplo, al sujeto cartesiano del ego cogito; se dice que es, en realidad, el blanco, masculino, etc. ${ }^{36}$, cuando justamente está vacío de propiedades de tal tipo para poder ser realmente universalizado, y, entonces, resulta tan absurdo hablar de exclusión como decir que la serie natural de los números excluye a los rojos, cuando esta cualidad no entra en la definición de la categoría de número. Se califica la posición de "racismo epistémico", sin distinguir entre una interpretación concretista ideológica y el sistema teórico-filosófico al que pertenece; no se diferencia entre doxa y episteme. Aquella abstracción, sin embargo, tenía una dimensión crítica, permitía contestar a las autoridades de su época, los argumentos de autoridad en el contexto de las guerras de religión; en tal contexto se hacía necesario encontrar un criterio seguro para evitar las imposiciones dogmáticas. Leibniz, un poco más tarde, soñaría con una lengua universal, characteristica universalis, que pudiera resolver todo conflicto, pues la raíz de estos se ubicaría en la multiplicidad de lenguas y culturas; este también era el fondo histórico de sus preocupaciones matemáticas ${ }^{37}$-recordemos que Leibniz, que nació dos años antes del final de la Guerra de los Treinta años, vivió en una Alemania que había perdido el 35\% de su población en las fratricidas guerras religio-

\footnotetext{
R. Grosfoguel, "What is racism?”, op. cit., p. 270.

36 Según esto, Grosfoguel puede decir que el ego cogito, el yo trascendental no es el yo africano, el yo indígena americano, etc., es el yo blanco francés, alemán... Grosfoguel aplica la misma idea al sujeto trascendental kantiano afirmando que ahí es más explícita ("Hacia un pluri-versalismo...", op. cit., p. 204). Es este un topos que se repite en todos los decoloniales. E. Dussel, Anti-cartesian Meditations, op. cit., p. 72; A. Quijano en "Colonialidad y Modernidad/Racionalidad”, Perú Indig. 13(29), pp. 11-20, 1992, p. 14.

37 S. Toulmin, op. cit., pp. 146 ss.
} 
sas. En definitiva, cartesianos y leibnizianos pretendían un método racional de resolver las disputas y de poner fin al odium theologicum. Cuando se cree contextualizar y se dice que el sujeto desencarnado tenía la carne del blanco europeo y que, por tanto, cumplía una función ideológica, se hace una lectura referente a un discurso ideológico que pudo ser usado en un tiempo, pero que ya es ajeno a la filosofía cartesiana en sí misma, no se comprende el contexto que hacía que la propuesta de sujeto fuera abstracta, se sustrajese a las particularidades, que solo conducían al conflicto. No se comprende el contexto que explicaba la descontextualización.

Un error semejante comete Grosfoguel cuando nos dice que, si bien Marx evita el error, característico de la filosofía moderna, de la abstracción del sujeto de enunciación, que es puesto en relación con las clases sociales, interpreta en realidad la clase obrera como masculina. Grosfoguel confunde, de nuevo, un sujeto teórico con un sujeto empírico; el sujeto clase obrera en Marx es definido por conceptos como plusvalía, valor de cambio, fuerza de trabajo, y la propiedad de género no entra en la teoría, cualesquiera que fuesen de facto las doxai al respecto del individuo de Treveris, Karl Marx.

Para Grosfoguel la tesis del universalismo abstracto (enunciados universales y abstracción del sujeto de enunciación) forma parte del racismo epistémico. Según esto, solo un "sujeto blanco-europeo-masculino-heterosexual" podría acceder al conocimiento en el marco de esa episteme. No sabemos, entonces, cómo se podrían explicar los casos de las aportaciones a la teoría de los números del indio Ramanujan, las hechas a la química por la señora Curie, o a la computación por el homosexual Turing, pues incumplen claramente aquella condición, salvo que se conteste con la tautología de que en el momento que adoptan la universalidad han perdido su condición. Tampoco podría explicarse desde aquí que haya sido la misma tradición occidental criticada la que cuestionara la idea de un sujeto descarnado, ajeno a todo contexto, ahistórico. Dentro de su determinismo geográfico -a pesar de haberse declarado contra él-, Grosfoguel solo puede reconocer la posición del francomartinico Aimé Césaire como una posición alejada del universalismo vacío y del particularismo localista. En la interpretación del puertorriqueño, Césaire nos aportaría, más que universales, pluriversales; conceptos llenos de determinaciones particulares y en diálogo con los otros, sin que se nos explique nada acerca de las posibilidades del diálogo o de la coexistencia de estos pluriversales o el criterio de discriminación cuando son contradicto$\operatorname{rios}^{38}$. Un problema semejante encontramos en la ecología de los saberes de Boaventura.

\subsection{Afuera o mediaciones}

Esa especial geopolítica del conocimiento unida al concepto de cultura como totalidad homogénea, conduce necesariamente a tener que situarse en exterioridad absoluta respecto de la cultura criticada. Eso es lo que, en

\footnotetext{
38 R. Grosfoguel, "Hacia un pluri-versalismo...” op. cit., pp. 209 ss. Mignolo hablará de "diversalidad" ("Geopolítica del conocimiento y diferencia colonial”, op. cit., p. 33).
}

definitiva, representa la formulación ambigua de Mignolo de un border thinking, pues se trata de una frontera estanca en que no se está realmente en el border sino del otro lado de él. Eso es lo que llevó a Boaventura a responder sosteniendo la imposibilidad de ocupar tal espacio aunque solo fuera por la larga impregnación de la cultura occidental durante medio milenio. Esa posición, en un registro más temperado, es la que hace que Boaventura postule su transición paradigmática, en la que lo nuevo aún debe ser pensado con lo viejo ${ }^{39}$.

Según Mignolo, Boaventura hace una crítica débil a la modernidad debido a que es interna a la misma, dimensión que Boaventura no tiene dificultad en aceptar. El autor portugués busca elementos en la modernidad que han sido reprimidos, para construir con ellos un paradigma de transición o transición paradigmática. Mignolo no acepta este enfoque y propone un "paradigma otro". Según el argentino, Boaventura no estaría haciendo sino "una crítica eurocéntrica del eurocentrismo de la modernidad occidental" - una crítica que dirige también a Wallerstein y a los posmodernos-, no haría sino descentrar el eurocentrismo y dispersarlo en los saberes subalternos, en las otras culturas. Boaventura acepta la necesidad de tener más presente en todos los planteamientos la cuestión colonial, pero nada más. Boaventura, consciente de estas diferencias, distingue su poscolonialismo del de Mignolo y otros, y lo denomina poscolonialismo de oposición.

La modernidad no parece estar del todo acabada para Boaventura, aunque afirme que la emancipación ya no es posible con los instrumentos modernos: "Las promesas de la modernidad -la libertad, la igualdad y la solidaridad- siguen siendo una aspiración para la población mundial" ${ }^{40}$. Sostiene, pues, una posición más matizada respecto de la modernidad:

Esto significa, antes de nada, que sólo a partir de la modernidad es posible trascender la modernidad. Si es verdad que la modernidad no puede ofrecer solución a los excesos y déficits de los que es responsable, no es menos verdad que sólo ella permite desearla. De hecho, podemos encontrar en la modernidad todo lo que es necesario para formular una solución; todo, menos esa solución ${ }^{41}$.

En lo que denomina principio de regulación (que diferencia del de emancipación, los dos principios definitorios de la formación moderna) distingue las esferas del mercado, del Estado y de la comunidad, y nos dice que esta última, a diferencia de las otras dos, ha resistido el dominio de la racionalidad científica y cognitivo instrumental, pero ha sido el elemento más marginado. Con todo, sobre él cabría apoyar un principio de emancipación. La colonización de la solidaridad se daría a través del Estado de bienestar. El pilar de la emancipación y la racionalidad estético-expresiva habrían resistido me-

\footnotetext{
B. de Sousa Santos, Una epistemología del sur, op. cit., pp. 357-359.

40 B. de Sousa Santos, Renovar la teoría crítica y reinventar la emancipación social, Buenos Aires, Clacso, 2006, p. 14.

41 B. de Sousa Santos, Crítica de la razón indolente, op. cit., p. 82. Habría que examinar si Boaventura se reconoce más deudor de la Modernidad antes de la constitución de su concepto de epistemologías del sur que después, cuando se sumerge más en las investigaciones de poscolonialismo.
} 
jor la colonización de la ciencia. La industria del ocio colonizaría el concepto de placer esencial al arte. Conforme a esa diferenciación de dos principios, se darían dos tipos de conocimiento: "El paradigma de la modernidad contiene dos formas principales de conocimiento: el conocimiento-emancipación y el conocimientoregulación" ${ }^{42}$, y el problema es que se habría perdido el equilibrio necesario entre ellos, imponiéndose el segundo sobre el primero.

El intento por parte de Mignolo de definición desde un afuera no deja de compartir con la "cultura occidental" aquello que se le criticaba. Dussel denunciaba, como vimos, la idea de una Europa que reconstruía endógenamente su historia, que hacía nacer en Grecia, desconsiderando todo lo que debía a las culturas egipcias y orientales, muy superiores, en una continua depuración de lo considerado externo, y no es otro el modelo de cultura que vemos aquí, ahora ya no como reconstrucción retrospectiva sino como ideal proyectivo. Mignolo se esfuerza en considerar solo a los autores de las colonias, buscando una especie de pureza en la que se expurga lo considerado externo. Así se cita, por ejemplo, a los franco-martinicos Aimé Césaire y Frantz Fanon pero sin observar todo lo que ellos deben al pensamiento de la metrópoli en que se formaron. Una deuda que tampoco se recuerda cuando se abordan las primeras críticas elaboradas que desde el Nuevo Mundo se hicieron del colonialismo español como la del indígena peruano Guamán Poma (XVI-XVII) que en Primer nueva coronica y buen gobierno (terminada en 1616), obra de historiografía única que recoge la cultura del mundo andino, critica a los cristianos colonizadores por incumplir con los mandamientos, con los propios textos bíblicos, a diferencia de los idólatras incas, que adorando otros dioses, cumplían sin embargo con la moral, con los mandamientos, por lo que en la práctica eran mejores "cristianos" que los españoles. Guamán trata de integrar en su cristianismo las cosmovisiones indígenas; los pueblos indígenas vienen a ser en él "los pobres de Cristo". No se advierte cómo la cultura en la que se habían formado también posibilitaba su cuestionamiento $^{43}$. Se da, pues, una abusiva simplificación e incomprensión del modo de operar de la crítica, de las deudas teóricas; una comprensión muy estrecha, para decirlo en términos althusserianos, del modo de producción de la teoría. Y del modo de configuración de las culturas. Ninguna cultura nace como enteramente otra ni se constituye desde afuera alguno.

43 Santiago Castro y E. Mendieta también extienden su crítica a toda utilización de las categorías de la filosofía occidental, que entienden caracterizada por una misma metafísica asociada a una voluntad de poder. Por ello, nada podría hacerse con ellas. Eso es lo que condenaría a los mismos poscoloniales que las usaron. Castro llega a afirmar que incluso las salidas propuestas por el pensamiento postmetafísico (Nietzsche: el arte; Heidegger: contemplación mística; Deleuze: el deseo; Vattimo: religión débil) están marcadas por la colonialidad. "La translocalización discursiva de "Latinoamérica" en tiempos de la globalización”, en S. Castro-Gómez, E. Mendieta, Teorías sin disciplina (latinoamericanismo, poscolonialidad, y globalización en debate), México, Porrúa, 1998.
}

\subsection{Idealización, acrítica, paternalismo}

Determinismo y exterioridad se asocian a menudo a una continua idealización -que no deja de ser paternalistade lo que queda del otro lado, que en ningún caso es sometido a crítica. $\mathrm{Si}$, ciertamente, la invisibilización de culturas ha sido más que frecuente, a veces también parece darse la inversión estricta, por la que se pretende visibilizar todo como si sin más hubiera de ser aceptado.

Los ejemplos pueden multiplicarse: Aníbal Quijano reconoce que toda cultura tiene una cosmovisión, una perspectiva de totalidad aplicada a la sociedad, pero mientras que la de Occidente sería meramente instrumental y unificadora, la de todas las demás no incurrirían en tal falta, serían respetuosas con las diferencias y se abrirían al otro ${ }^{44}$.

Grosfoguel abunda en los casos que nos ofrece de esta posición, como su idea de que ninguno de los grandes males que el diagnostica, patriarcalismo, racismo, antiambientalismo, explotación fuese conocido en la América precolombina.

Puede observársele alabar como alternativa la concepción política de los zapatistas, por la razón principal de que no sea occidental, pues se basaría en los indígenas tojolabales, los cuales usan el método de "andar preguntando", esto es, los zapatistas no imponen sino que primero preguntan a la gente. "El «andar preguntando» plantea una manera otra de hacer política muy distinta al «andar predicando» de la cosmología judeocristiana occidental reproducida por marxistas, conservadores y liberales por igual". Además, en Occidente no tendríamos la concepción de la democracia en la que el que manda obedece. "El «andar preguntando» está ligado al concepto tojolabal de democracia entendida como «mandar obedeciendo» donde «el que manda obedece y el que obedece manda», lo cual es muy distinto de la democracia occidental donde «el que manda no obedece y el que obedece no manda»" 45 . A esto, Grosfoguel lo llama una "cosmología otra", para subrayar su distancia con la nuestra.

Tal como la cultura occidental moderna estaba abocada al mal, la del otro lado parece, por lo mismo, inmunizada $^{46}$. Así, para Mignolo, la Modernidad se distingue por su idea del tiempo (lineal) y de la historia, mientras que las culturas indígenas se situarían en el espacio, conduciendo lo primero a la dominación o diseño global que se trata de imponer.

Boaventura también parece dejar llevarse por estos arrobos idealizantes. La epistemología que promueve "hace posible recuperar desde pueblos milenarios que han logrado la recreación de su hábitat a través de una relación simbiótica directa con los ciclos o procesos de génesis y muerte de la Madre Tierra (Pachamama). La sabiduría ancestral que porta el pensamiento de estos pueblos originarios expresados por sus tradiciones, ritos, magias, hasta sus representaciones antropomórficas de la civilización son síntomas de que el ocaso de la

\footnotetext{
44 A. Quijano, “Colonialidad y Modernidad/Racionalidad", op. cit., 1992, p. 19.

45 R. Grosfoguel, "Hacia un pluri-versalismo...", op. cit., p. 209.

46 Cf. O. Beluche, "Epistemologías del sur: aportes, limitaciones y errores", www.sinpermiso.info, 23 de febrero 2018.
} 
civilización, no muere con Occidente, sino que renace desde el Sur con el Sumak Kawsay" ${ }^{47}$.

Según Boaventura, la razón metonímica occidental opera por dicotomías que esconden una jerarquización: hombre/mujer, norte/sur, cultura/naturaleza, lo que no harían otras racionalidades orientales, que son más holísticas. La razón occidental estaría imposibilitada para pensar fuera de la totalidad que demarcan estas dicotomías, incapaz de pensar un polo sin remisión al otro.

En fin, como suele suceder, la idealización no pocas veces se ve acompañada por la magnificación, en palabras de Mignolo: "Fanon es equivalente a Kant", "Guaman Poma de Ayala podría considerarse como el Aristóteles del Perú colonial" $"$.

Se entiende, entonces, que algún crítico se haya visto obligado a señalar lo obvio, que "las lenguas indígenas no son inherentemente igualitarias o liberadoras por no ser europeas" $" 49$. Ante estas muestras, el gran relato de la conquista y de las culturas indígenas puras e inocentes resulta abusivo para un análisis crítico.

En esa línea paternalista llega a afirmarse explícitamente que la operatividad de la crítica debe ser distinta en un campo y en otro. Después de indicarnos que los procedimientos críticos en la zona del ser son distintos a los de la zona del no-ser, que no se pueden generalizar, Grosfoguel nos previene contra las críticas antiesencialistas de postestructuralistas y posmodernos:

En la zona del no-ser, inflar y construir identidades y epistemologías fuertes con meta-narrativas sólidas es necesario en el proceso de reconstrucción y descolonización. Reconstruir identidades y epistemologías fuertes es un requisito para reconstruir en la zona del no-ser lo que la colonialidad ha destruido y reducido a la inferioridad a través de siglos de expansión colonial europea ${ }^{50}$.

Grosfoguel nos viene a plantear para la teoría la misma estrategia, cosechadora de derrotas, que se emplea en la practica política: la democracia y horizontalidad está bien para los desarrollados, pero aquí, caudillos y disciplina; el derecho a no encerrarse en una identidad está bien para el norte, pero para el sur es necesario crear esas cárceles psíquicas y fetiches históricos. Y hace esta conocida acusación: "Estos métodos de la izquierda occidentalizada terminan siendo cómplices con el racismo colonial histórico de hacer inferior el conocimiento y las epistemologías producidas por los sujetos coloniales". La teoría crítica queda para los del norte:

La desconstrucción, des-esencialización y des-totalización radical son métodos fundamentales de descolonización dentro de la zona del ser, que siempre y cuando no se extrapolen al pensamiento crítico de los sujetos colonizados para descualificarlos, constituyen un paso im-

47 B. De Sousa, "Epistemologías del Sur", Revista Internacional de Filosofia Iberoamericana y Teoría Social, Año 16. No 54 (JulioSeptiembre, 2011), pp. 17-39, aquí p. 17.

48 W. Mignolo, "Geopolítica del conocimiento y diferencia colonial", op. cit., p. 12.

49 J. Browit, "La teoría decolonial: buscando la identidad en el mercado académico", Cuaderno de Literatura, vol. VIII, n 36, jul-dic, 2014, $25-46$, p. 38

50 R. Grosfoguel, "What is racism?", op. cit., p. 272. portante para los sujetos imperiales comenzar un proceso descolonial $^{51}$.

\section{Otras epistemologías}

El dominio colonial de la cultura occidental tendría como efecto mayor, según todo el planteamiento decolonial, lo que es denominado violencia epistémica o epistemicidio, esto es, la inferiorización, desprecio o aniquilación de otras culturas, de las otras culturas. Según Boaventura, ese efecto de la modernidad occidental está en relación con lo que caracteriza como pensamiento abismal, entendiendo por tal un pensamiento que traza una línea de exclusión de todo aquello que no se ajusta a sus pautas, y esa línea de exclusión coincide con el territorio colonial sometido a la lógica de la apropiación/violencia, mientras que lo incluido se guiaría por la de la regulación/ emancipación (orden y progreso, experiencia y posibilidad de mejora, expectativa, posibilidades de cambio o transformación); aquella sería el fundamento invisible de esta. En la ciencia y el derecho se manifestaría esa línea que separa uno y otro lado. La ciencia como único saber cierto que condena los demás, todo lo que no se ajusta a sus formas, y el derecho que sería incapaz de absorber el gran espacio de lo alegal. Boaventura no repara en que los efectos que señala respecto a la ciencia y al derecho son de índole general y afectarían tanto a territorios coloniales como a la metrópoli. La realidad histórica es que no ha habido una separación estricta entre los fenómenos de exclusión, por lo que se refiere a la teoría, entre Europa y Latinoamérica: la postulación de la ciencia y de la filosofía modernas llevaron en un lado y otro al orillamiento, marginación y desaparición de otros saberes. El llamado epistemicidio no significaba necesariamente una persecución intencionada, ni tampoco exclusiva de las colonias. Ya nos hemos referido al fenómeno, puesto de relieve por Toulmin, del estrechamiento que en el campo del conocimiento se dio en el paso del humanismo del XVI al imperio científico del XVII, que supuso el descuido de la oralidad (retórica), de o particular (ética aristotélica), de lo local (abandono de la etnografía, de la historia) y de o temporal, que conllevaría, en general, una desatención a la filosofía práctica $^{52}$. Y alguien podría citar, lo que los historiadores no han dejado de observar, un efecto semejante en lo que se refiere a las formas económicas no capitalistas. Mignolo se refiere solo al otro lado, a las culturas andinas que no se guiaban por la acumulación, pero lo mismo ocurría en el precapitalismo europeo, muchas comunidades quedarían destruidas o estancadas.

El decolonialismo opondría a los efectos de epistemicidio, la emergencia de otras epistemologías. Boaventura lo ha acuñado en la denominación, a veces metafórica, a veces geográfica, de "epistemologías del sur", Mignolo habla de "border gnoseology".

Hay que decir que, en este punto, observamos en los diversos autores, menos ciertamente en Boaventura

\footnotetext{
Idem.

52 S. Toulmin, Cosmópolis, op. cit., pp. 60 ss.
} 
aunque también, una frecuente falta de cuidado conceptual. El término epistemología y sus derivados se usan a menudo sin precisión alguna, valiendo por lo general para designar sin más un conjunto de conocimientos o lo tenido por tal ya por toda una cultura o solo por algunos de sus miembros. Por ejemplo, Mignolo afirma, con ese grado de generalidad antes apuntado: "Las densidades de la experiencia colonial son el lugar del que surgen las epistemologías" 53 . Se habla globalmente de una "epistemología occidental" y, conforme a ello, se traza el proyecto de desarrollar perspectivas desde un total afuera de esa epistemología. Así, aplica su planteamiento de border thinking a este campo de la epistemología y de a hermenéutica, y formula la noción de Border gnoseology como un intento de teorizar el conocimiento desde fuera de la perspectiva de la epistemología occidental.

Boaventura es más consciente de los problemas teóricos (relativismo, exterioridad, esencialismo, etc.), e intenta tender puentes (transición paradigmática, ecología de los saberes, traducción, etc.), mientras que Mignolo lo dispone todo de manera binaria y excluyente. El autor portugués es, sin duda, el más informado en cuestiones de teoría de la ciencia y nos ofrece una definición más precisa de epistemología, aunque no siempre sea consecuente con ella. "Epistemología es toda noción o idea, reflexionada no, sobre las condiciones de lo que cuenta como conocimiento válido" 54 . Los múltiples conceptos con los que ha ido construyendo su obra son a menudo poco contrastados empíricamente; apenas se citan ejemplos y casos, por lo que, en el plano general en que se mueve, es difícil no estar de acuerdo, pero solo podríamos evaluarlos si operara con mayor concreción.

De todos modos, Boaventura sabe que la defensa de lo que llama epistemologías del sur conlleva no pocos problemas y quiere evitarlos, como, por ejemplo, los de la inconmensurabilidad y el del relativismo radical, pero su respuesta no es muy satisfactoria. Aboga por lo que llama una ecología de los saberes (frente a la que define como monocultura de la ciencia moderna) en que ninguno excluya a otro, llama a un diálogo entre ellos, a saber traducirse. No considera que quepa una epistemología general, pero inmediatamente tiene que reconocer que algo por el estilo es necesario, y entonces propone una especie de epistemología general negativa o residual, una epistemología general para acabar con la epistemología general. Curiosamente, se ve en la tesitura de tener que introducir algún criterio para cuando dos epistemes no son compatibles, pero su propuesta no parece muy convincente; opta por proponer cierto pragmatismo, el criterio de "intervención en el mundo", "en lo real", no en función de la objetividad de la representación, sino del éxito de la intervención, pero ese éxito sería medido por su carácter integrador de las gentes que participan de esa episteme, lo que incluiría lo ético y lo práctico ${ }^{55}$. No sabemos cómo podría ser esto aplicado en la mayor parte del conocimiento científico teórico, situaciones de aplicabilidad aparte.

\footnotetext{
53 W. Mignolo, "Geopolítica del conocimiento y diferencia colonial", op. cit., p. 12.

54 B. De Sousa Santos, Epistemologías del sur. op. cit., p. 7.

55 B de Sousa Santos, "Para alem do pensamento abissal. Das linhas globais a uma ecologia de saberes", Novos estudos, 79, nov. 2007, pp. 71-94, aquí p. 90
}

Dado que el denominado monocultivo occidental de la ciencia es el más determinante, Boaventura se demora en él. Sin embargo, su crítica a lo que llama paradigma científico (que incluye a las ciencias naturales) ${ }^{56}$ es, en realidad, a un paradigma ya en declive, el que representa el positivismo, hace tiempo puesto en cuestión por el llamado logos occidental eurocéntrico. Por eso, todas sus pertinentes objeciones al respecto suenan a algo ya pretérito: división sujeto/objeto, natura/cultura, reducción de lo complejo a leyes simples formuladas matemáticamente, verdad como representación transparente de la realidad, mecanicismo determinista, desconexión de la ciencia con otros saberes que desprecia, causalidad funcional y ausencia de causas últimas.

Su frecuente falta de concreción es ya máxima cuando habla de algo tan delicado como "los conocimientos alternativos al conocimiento científico -conocimientos populares, indígenas, campesinos, etc.-" ${ }^{57}$ pues no precisa en que campo (¿física, medicina, química?...) serían realmente alternativos.

Boaventura nos habla de crisis de la ciencia, pero a menudo su diagnóstico apunta no tanto al conocimiento estrictamente científico como a sus usos o a su lugar en los distintos campos sociales, a su relación con otros discursos o saberes. Sin duda, es posible que no queramos que determinadas áreas o contextos sean regidos por técnica o ciencia o, incluso, verdad alguna, puede que no sea deseable que se usen técnicas psicológicas precisas en nuestra relación con los otros, o que no queramos saber de nuestro futuro biológico o que ningún algoritmo sustituya el juicio de un magistrado, que no tecnifiquemos más los campos de cultivo (empleo de química, etc.), que no se asuman riesgos excepcionales en determinadas experimentaciones, que no se emplee la ingeniería genética en eugenesia positiva, que no se prosiga determinada línea de investigación, etc., pero esto no afecta en nada a la validez del conocimiento sino, como decimos, al lugar de la ciencia en una cultura o incluso, si se quiere, dicho foucaultianamente, a nuestro régimen de verdad.

Esta imprecisión y generalizaciones resultan muchas veces, entonces, abusivas. Por ejemplo, se nos dice que "la nueva racionalidad científica es también un modelo totalitario, en la medida en que niega el carácter racional a todas las formas de conocimiento que no se adecúen a sus principios epistemológicos", y señala que esa es su "característica fundamental". Sin embargo esto, hoy, sería difícil de sostener, al menos a la luz de la teoría de la ciencia e incluso de la reflexividad práctica del científico informado, pues lo que se niega no es el "carácter racional" de otros discursos sino simplemente su carácter no científico, una distinción por lo demás absolutamente necesaria $^{58}$.

B. de Sousa Santos, Una epistemología del sur, op. cit., p. 336. B. de Sousa Santos, "La renovación...", op. cit., p. 17.

Montserrat Galceran, defiende las posiciones decoloniales. Trata de profundizar en la espinosa cuestión del universalismo, pero no entra realmente en su problemática teórica. Según esto, no podemos explicarnos, por ejemplo, si el que en un campo como el de las ciencias físicas y matemáticas se de universalismo y no así en otros campos es debido a alguna condición interna, digamos de iure, o solo es algo fáctico. Es partidaria de la solución de Boaventura de la ecología de 


\section{Un concepto equivocado de cultura}

Subyace a todo este planteamiento decolonial un determinado concepto de cultura que hemos venido poniendo de relieve. Esta es entendida como una esfera homogénea, holísticamente definida y perfectamente delimitable respecto a otras. Un concepto, por lo demás, muy occidental y moderno, surgido en el ámbito de la filosofía alemana pero con antecedentes en toda la Europa ilustrada, que Herder definió y el romanticismo promovió $^{59}$. La cultura parece tener un origen puro, y se define como ente de una pieza, sin observar su carácter híbrido, salvo excepciones de aislamiento, a menudo de carácter plural y conflictivo. Las culturas son conjuntos de contornos borrosos, diversos sincrónica y diacrónicamente, compuestos por elementos y estructuras o marcos no perfectamente delimitados en difícil equilibrio, que no pocas veces son disfuncionales unos respecto de otros, o se superponen, no sin rozamientos, que cambian siguiendo ritmos diversos. Por eso no es tan fácil hablar de un afuera de una cultura cuando esta no está excepcionalmente aislada. En realidad, ninguna cultura tiene un afuera demarcado, todas son porosas y suficientemente dúctiles como para integrar los elementos más extraños. Los marcos de una cultura constituyen una pluralidad de horizontes compartidos. No hay un marco omniabarcador que englobe a todos los demás. Incluso en una misma persona puede observarse esto que decimos de la difícil coexistencia y equilibrio de los marcos o estructuras, que no siempre son coherentes entre sí como puede verse en la cantidad de cosmovisiones y físicas superpuestas, del aristotelismo al galileismo, incluidos elementos de relatividad einsteniana que a menudo coexisten en una misma mente. Gramsci habló mucho de esto al referirse a un elemento tan característico de una cultura como el sentido común. Puede haber ciertamente un marco más abarcador que otro, que impregne más extensamente la vida de las gentes, ese que proporcione lo que suele entenderse como sentido, como, por ejemplo, fue la religión en una época determinada, pero ni siquiera esto deja de convivir en negociación continua de equilibrio con el resto de los marcos. Las experiencias tenidas en un ámbito, el de la guerra, el del trabajo, el de la investigación, pueden chocar con el marco dominante que, por otra parte, tampoco es en sí tan unitario como pretende. El cristianismo como marco dominante en una época no es unitario, tiene diversas interpretaciones, y tampoco es tan envolvente como para que otros marcos no se desarrollen en direcciones diversas, no consistentes con él. En suma, la cultura es algo poroso, heterogéneo, de equilibrios inestables, plural, no del todo consistente, sin un marco monódico omniabarcante. No tiene, pues, un afuera absoluto, ya que no es algo cerrado, por lo que lo que se presenta como afuera siempre puede penetrar, no tiene ningún obstáculo definitivo que lo mantenga en la exterioridad. El afuera es solo una contingencia. Justamente esa apertura, esa porosidad, pluralidad, ese no-cierre es lo que posibilita el continuo intercambio, el diálogo, el préstamo, la hibridación.

Tiene razón, pues, Browit, cuando se pregunta si no se están reesencializando las culturas precolombinas, considerándolas puras cuando ya hace siglos que han sido hibridadas ${ }^{60}$. El mismo Boaventura, que no está a salvo de esta crítica, observa este aspecto cuando afirma que los poscoloniales esencializan Europa, la toman como algo homogéneo, unitario, al que se le pueda oponer otro todo; transforman una parte de Europa en el todo. Y señala acertadamente que hay varias Europas, y una teoría crítica poscolonial tendría que estar a la altura de esta complejidad. La función ideológica de manejo de un concepto de cultura como este sería aquella señalada por Gustavo Bueno de "separar a unos grupos dados a cierta escala (naciones, etnias, clases sociales) respecto de otros de su misma escala o de otra superior" ${ }^{\prime 61}$.

\section{Bibliografía}

Althusser, L. y Balibar, E., Para leer El capital, trad, M. Harnecker, Madrid, S. XXI, 1972.

Álvarez Yágüez, J., "La esclavitud invisible”, Debats, n 129, 2015/4.

Amorós, C., "El feminismo, senda no transitada de la Ilustración", Isegoría, 1, 1990.

Bahmbra, G.K., Rethinking Modernity: Postcolonialism and the Sociological Imagination, Palgrave MacMillan, 2007.

Beluche, O., "Epistemologías del sur: aportes, limitaciones y errores", www.sinpermiso.info, 23 de febrero 2018.

Braudel, F., El mediterráneo, México, FCE, 1987.

Browit, J., "La teoría decolonial: buscando la identidad en el mercado académico", Cuaderno de Literatura, vol. VIII, n 36, jul-dic, 2014.

Buck-Morss, S., Hegel y Haití. La dialéctica amo-esclavo: una interpretación revolucionaria, trad., F. Rodríguez, Buenos Aires, Norma, 2005.

Bueno, G., El mito de la cultura, Barcelona, Prensa Ibérica, 1996.

Casassas, D., La ciudad en llamas. La vigencia del republicanismo comercial de Adam Smith, Barcelona, Montesinos, 2010.

Castro-Gómez, S., Mendieta, E. Teorías sin disciplina (latinoamericanismo, poscolonialidad, y globalización en debate), México, Porrúa, 1998.

los saberes y del diálogo y la traducción pero nada nos dice acerca de la enrevesada cuestión de cuales serían las condiciones de las pretensiones de validez que cualquier diálogo supone. M. Galceran, $L a$ bárbara Europa. Una mirada desde el postcolonialismo y la descolonialidad, Madrid, Traficantes de sueños, 2016.

59 G. Bueno, El mito de la cultura, Barcelona Prensa Ibérica, 1996, p. 50 .

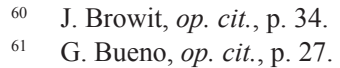


Castro Orellana, R., "Diferencia colonial y pensamiento fronterizo. El privilegio de Walter Mignolo", en D. Abraldes (coord.), Ideas que cruzan el Atlántico: Utopía y modernidad latinoamericana. Madrid, Escolar y Mayo, 2015.

- "Sistema mundo y transmodernidad. Una lectura crítica", en Política Común, vol. 10, 2016, https://doi.org/10.3998/ pc.12322227.0010.004.

De Sousa Santos, B., Una epistemología del sur, (Ed J.G. Gandarilla), México, Clacso, S. XXI, 2009.

- Crítica de la razón indolente, Bilbao, Desclee de Brouwer, 2003.

- Renovar la teoría crítica y reinventar la emancipación social, Buenos Aires, Clacso, 2006.

- "Para alem do pensamento abissal. Das linhas globais a uma ecologia de saberes", Novos estudos, 79, nov. 2007, pp. 71-94.

- Conocer desde el sur. Para una cultura política emancipatoria, Lima, Facultad de C. Sociales, 2006.

- "Epistemologías del Sur", en Revista Internacional de Filosofia Iberoamericana y Teoría Social, Año 16, no 54 (julio-septiembre, 2011), pp. 17-39.

Dussel, E., Politics of Liberation. A Critical World History, transl. Th. Cooper, London, SCM Press, 2011.

- "Europe, Modernity and Eurocentrism", Nepantla: Views from South 1, 3, Duke U. Press, 2002.

- Hacia una filosofia política crítica, Bilbao, Desclée de Brouver, 2001.

- 1492, El encubrimiento del otro. Hacia el origen del "mito de la modernidad”, La Paz, Plural, 1994.

- Anti-Cartesian Meditations and Transmodernity. From the Perspectives of Philosophy of Liberation, (ed, A. A. Vallega, R. Grosfoguel), The Hague, Amrit P, 2008.

Echevarría, B., Las ilusiones de la modernidad, México, UNAM, 1997.

Galceran, M., "Raza, Clase, Género. Descolonizando a la izquierda. Los estudios poscoloniales y decoloniales y la intelectualidad europea", Viento Sur, 160, oct., 2018.

- La bárbara Europa. Una mirada desde el postcolonialismo y la descolonialidad, Madrid, Traficantes de sueños, 2016.

Grosfoguel, R., "Hacia un pluri-versalismo transmoderno decolonial", Tabula Rasa. Bogotá, no 9, pp. 199-215, jul.-dic. 2008.

- "What is racism? Zone of being and zone of non-being in the work of Frantz Fanon and Boaventura de Sousa Santos", en J. Cupples, R. Grosfoguel (edited by), Unsettling Eurocentrism in the Westernized University, New York, Routledge, 2019, pp. 264-273.

Habermas, J., El discurso filosófico de la modernidad, trad, M. Jiménez Redondo, Madrid, Taurus, 1989.

Israel, J. I., Radical Enlightenment. Philosophy and the Making of Modernity 1650-1750, Oxford U. Press, 2001.

Koselleck, R., "Modernidad", en Futuro pasado. Para una semántica de los tiempos históricos, trad., N. Smilg, Barcelona, Paidós, 1993.

Marx, K., El capital, t. I, trad., W. Roces, México, F.C.E.1975.

Mignolo, W., Local Histories and Global Designs. Coloniality, Subaltern Knowledges and Border Thinking, New Jersey, Princeton U. Press, 2000.

- La idea de América Latina. La herida colonial y la opción decolonial, trad, S. Jawerbaum, J. Barba, Barcelona, Gedisa, 2008.

Quijano, A., "Colonialidad y Modernidad/Racionalidad”, Perú Indig. 13(29), pp. 11-20, 1992.

Schiwy, F., Castro-Gómez, S. Indisciplinar las ciencias sociales. Geopoliticas del conocimiento y colonialidad del poder: perspectivas desde lo andino, Quito, U. Andina Simón Bolívar, 2002.

Tatián, D., "La potencia de los esclavos. Conjetura sobre un silencio de Spinoza”, Revista Co-herencia, Vol. 15, nº 28, en.-jun, 2018, pp. 225-244.

Toulmin, S., Cosmópolis. El trasfondo de la modernidad, trad., B. Moreno, Barcelona, Península, 2001. 